\title{
Rol e importancia de las leyes de bases en el Derecho Administrativo chileno
}

\author{
Rosa Gómez González*
}

\begin{abstract}
RESUMEN
El presente artículo tiene por objeto analizar sucintamente el rol que desempeñan en el Derecho Administrativo las leyes de bases, determinar si efectivamente existe una primacía de estas sobre las leyes especiales y establecer su posible similitud con los "códigos" existentes. Asimismo, se estudiará su importancia y cómo han influido en el microsistema respectivo, unificándolo y llenando las lagunas que eventualmente pueden existir en las leyes especiales, junto con hacer particular mención a la incorporación de principios que según sus enunciados prescriptivos informarán la interpretación jurídica y, en su caso, la aplicación judicial de los preceptos particulares.

Bajo tal predicamento se discutirá la necesidad de dictación de las mismas para luego señalar si se precisa su existencia en otros ámbitos del Derecho Administrativo, como sería en el ámbito sancionador.
\end{abstract}

Derecho Administrativo - códigos - leyes de bases - primacía - microsistemas

\section{Role and importance of framework legislation in the chilean Administrative Law}

\begin{abstract}
This article aims to analyze the role they play in the administrative law framework laws, determine whether there is indeed a priority of these on special laws and establish their possible similarity with existing "codes". Also, its importance will be discussed and how they have influenced the respective microsystem, unifying and filling gaps that may exist on the special laws, with special mention to the incorporation of principles as set out prescriptive inform their legal interpretation and, where appropriate, the judicial application of particular provisions. Under such a predicament the need for enactment of these will be discussed and then indicate whether its existence is required in other areas of administrative law, as it would be in the penalty area.
\end{abstract}

Administrative Law - Codes - Basis Act - Primacy - Microsystems

* Abogada, Magíster en Derecho Regulatorio. Investigadora del Programa de Derecho Administrativo Económico de la Pontificia Universidad Católica de Chile. Alumna del Programa de Doctorado en Derecho de la Pontificia Universidad Católica de Valparaíso. Beneficiaria Beca CONICYT-PCHA/Doctorado Nacional/2016-Folio No 21160419. Correo electrónico: rsgomez@uc.cl

Artículo recibido el 28 de agosto de 2015 y aceptado para su publicación el 30 de agosto de 2016. 


\section{Los microsistemas del Derecho Administrativo}

L a estabilidad del marco jurídico en el que actúan y se desenvuelven las personas les brinda mayor seguridad al momento en que estas adopten sus decisiones; prueba de ello estaría dada precisamente en nuestro país, en donde las políticas reformistas del gobierno actual han frenado la inversión y el crecimiento económico a la espera de saber qué va a pasar y cuáles van a ser las nuevas reglas.

Reflejo de esta seguridad, según Irti, serían los códigos -el que colocando como ejemplo el Código Civil italiano de 1865-, expresa que el legislador se ilusiona con la redacción de un repertorio de figuras y disciplinas típicas, de modo que el juez poco o nada puede añadir a la comprobación del hecho concreto y a la lectura del texto normativo. La técnica del supuesto de hecho elimina o reduce las cláusulas generales a lo que se adiciona la pretensión de ausencia de lagunas y la ambición de dar respuestas a todos los problemas de la realidad ${ }^{1}$. Así, podemos decir que los códigos constituyen estatutos orgánicos del actuar de las personas bajo la fórmula de una secuencia ordenada de artículos, que le brindan armonía y unidad al sistema de que se trate.

Ahora bien, esta intervención ordenada y reflexiva del legislador no se aprecia con esa intensidad en el Derecho Administrativo, este se ha ido construyendo paulatinamente a base de decisiones jurisprudenciales y de la dictación de leyes aisladas y particulares destinadas a atender una situación particular, ello responde a la evolutiva y cambiante realidad de esta disciplina jurídica.

En algunos ámbitos de esta rama jurídica se aprecia un movimiento de progresiva incorporación de sectores en otrora entregados a la libre disponibilidad de los particulares, lo que se ha practicado mediante diversas técnicas más o menos intervencionistas, entre estas, según la clasificación de Garrido Falla ${ }^{2}$, podemos señalar: a) la anexión, de áreas completas a la gestión administrativa; b) el protectorado, que implica que la actividad continúe siendo privada pero sujeta a la regulación estatal; c) las limitaciones, que comportan una restricción externa y coactiva de la actividad privada por normas de Derecho Público; y d) la infiltración, que aparentemente respeta la actividad privada bajo preceptos privados, pero en ciertos aspectos se regula por las normas de Derecho Público.

Desde esta perspectiva, la técnica legislativa ha sido reaccionaria ${ }^{3}$, lo que ha conllevado algunos problemas no menores, como lo son la falta de madurez de algunas

\footnotetext{
${ }^{1}$ Irti, N., La edad de la descodificación, José María Bosch Editor, Barcelona, 1992, pp. 20-21.

${ }^{2}$ Garrido, F. Tratado de Derecho Administrativo, Parte General, Volumen I, Instituto de Estudios Públicos, Madrid, 1970, $5^{\text {a }}$ edición, p. 149.

${ }^{3}$ Ejemplo de ello hay por montones, solo por mencionar algunos preceptos, está la Ley $\mathrm{N}^{0} 20.285$, Sobre Acceso a la Información Pública (que incluyó la creación del Consejo para la Transparencia); la Ley $\mathrm{N}^{\circ}$ 20.730, que regula el lobby y las gestiones que representen intereses particulares ante las autoridades y funcionarios; o las leyes $\mathrm{N}^{\circ}$ s. 20.900 y 20.915, sobre el fortalecimiento y transparencia de la democracia y sobre el fortalecimiento del carácter público y democrático de los partidos políticos y su modernización, respectivamente, dictadas para mejorar la regulación sobre el financiamiento de las campañas políticas, a propósito de la polémica generada por varios casos bullados públicamente (Penta y Soquimich) sobre la materia.
} 
instituciones, la omisión regulatoria (lagunas), la ausencia de una visión sistemática en cuanto a los efectos de algunos preceptos y la contradicción normativa ${ }^{4}$.

Por lo anterior, en el Derecho Administrativo impera una dispersión normativa de significativa relevancia, no existe una unidad sistémica sino que una pluralidad de microsistemas ${ }^{5}$, esto es, un conjunto de normas especiales que, promulgadas para particulares instituciones o clases de relaciones jurídicas, se enlazan en principios comunes de regulación ${ }^{6}$, atribuidas de una lógica y desarrollo propio, en donde hay una ausencia de codificación ${ }^{7}$, esto es, la inexistencia de un texto que organice sistemática y coherentemente la disciplina, por cuanto las materias propias de esta rama del Derecho siempre se han regulado, a lo largo de la historia, aisladamente.

$\mathrm{Al}$ efecto, hay quienes han postulado, siguiendo el caso norteamericano y su lógica eminentemente pragmática, un tipo de codificación que implique que el Estado asuma un rol activo en la compilación, indexación y codificación el ordenamiento jurídico, que importe una publicación periódica y actualizada, en papel y en una página web, de la ordenación $\log r a d a^{8}$.

${ }^{4}$ A lo expuesto, debemos agregar la nutrida normativa administrativista, la que no solo está compuesta por el texto constitucional y por leyes, sino que se integra de reglamentos, decretos, instrucciones, ordenanzas y actos administrativos, estos, en mayor o menor medida intervienen en la acción de los particulares. Aspectos que, por lo demás, escapan al objeto de este estudio.

5 No se trataría de un subsistema, ya que entre normas generales y especiales no se establece por consiguiente un nexo de subordinación ni las segundas están sujetas a los criterios de las primeras, en Irti, N., La edad de la descodificación, José María Bosch Editor, Barcelona, 1992, p. 59.

${ }^{6}$ Irti, N., La edad de la descodificación, José María Bosch Editor, Barcelona, 1992, p. 59.

7 Al efecto, debemos valorar los esfuerzos de Alejandro Vergara Blanco, quien ha empleado la terminología "Código" para reafirmar el rol de la doctrina como sistematizadora de las fuentes legales. El citado académico se vio enfrascado en un litigo con la Editorial Jurídica de Chile (empresa fiscal) como consecuencia de la publicación del "Código Administrativo General”, texto que contiene una recopilación sistemática de diversas leyes de la materia administrativa; la acción fue rechazada en primera y en segunda instancia, y finalmente por la Corte Suprema.

Junto con ello, debemos tener presente que mientras se discutía el asunto litigioso, Vergara Blanco recurrió ante el Tribunal Constitucional (TC), solicitando la declaración de inaplicabilidad por inconstitucionalidad del art. $2^{\circ}$ de la Ley $\mathrm{N}^{\circ} 8.828$, que establece un privilegio o monopolio de esa editorial para la edición oficial de los códigos que ha aprobado el legislador chileno; si bien el TC no acogió el recurso, señaló, en lo que interesa, en sus considerandos 60 y 76 que los códigos elaborados por el autor pertenecen al género de las monografías, esto es, de aquellas obras intelectuales que consisten en una "descripción y tratado especial de determinada parte de una ciencia, o de algún asunto en particular", siendo tales obras fruto de la libertad de expresión y de creación intelectual que la Constitución asegura y que, aunque se hayan titulado como "Códigos" no son producto de la actividad legislativa que exige la creación de Códigos de la República. Mayor información en: http://derecho.uc.cl/Derecho-UC-en-los-medios/profesor-alejandro-vergara-la-doctrina-juridicay-el-intento-fallido-de-confiscar-la-expresion-lcodigor.html, última visita el 3 de julio de 2015. También véase en Vergara Blanco, A., "Uso doctrinario de la expresión "código". Caso Editorial Jurídica de Chile con Editorial LexisNexis”, en: Revista de Derecho (Valdivia) Vol. XXVIII N 1, junio 2015, pp. 265-276.

${ }^{8}$ Montt S., "El nuevo Código Administrativo General: poniendo orden a un caos normativo al que nadie se había atrevido a enfrentar", en Revista de Derecho Administrativo Económico, 2005, No 14, p. 200. Acerca de la procedencia del proyecto el autor explica que "Existen, por cierto, sólidas razones para realizar un proyecto como este: a) desde un punto de vista político, se otorga a los ciudadanos un acceso más franco al ordenamiento jurídico, requisito exigido por la naturaleza democrática de nuestro sistema político y por la 
Por su parte, Bermúdez Soto ha señalado que el Derecho Administrativo no constituye un ordenamiento jurídico completo, porque carece de una ordenación y presenta una precaria densidad normativa. En efecto, agrega el autor, existe una escueta regulación general, no cuenta con una jurisdicción contencioso-administrativa o de procedimientos jurisdiccionales especiales, tampoco tiene una regulación respecto de la forma en que se debe impugnar judicialmente el acto administrativo, sus causales de nulidad, ni los efectos del incumplimiento de los contratos, así como tampoco existe una regulación concerniente a la forma, prueba y extinción de la responsabilidad de la Administración, entre otras omisiones legislativas?.

Ahora bien, como se sabe el Derecho Administrativo se construyó a partir de una abundante proliferación de normas ocasionales destinadas a regular un ámbito particular de la matriz administrativista, ello pese a que el Estado ha pretendido, con mayor o menor determinación, ser el señor absoluto del Derecho, concepción que concibe al Derecho como un simple mandato impuesto ad extra, pero no puede reconducirse a ese papel, el Derecho es una función social de articulación de sus miembros y de estos entre sí, labor que no se puede separar de una concepción material de justicia, de la que surgen las fuentes extralegales del Derecho ${ }^{10}$.

Con todo, en este propósito unificador, la Carta Fundamental constituye un marco infranqueable del Derecho Administrativo concebido como "sistema", noción que será abordada más adelante.

\section{LA CODIFICACIÓN}

Frente a lo expuesto ¿es posible practicar una “codificación” del Derecho Administrativo? Al respeto Enrique Silva Cimma manifestó que es imposible que la ley pueda regular todos los ámbitos en que se debe desenvolver la Administración del Estado; señala que el acto administrativo en muchas ocasiones se extiende más allá de la ley en donde aquella, en la mayoría de los casos, no alcanza a apreciar todas las circunstancias fácticas, en consecuencia la

presunción de conocimiento de la ley impuesta a todos los habitantes; b) desde un punto de vista económico, se trata de un bien público cuya provisión por el Estado tiene un sólido fundamento en la eficiencia. Empresas como LexisNexis pueden dedicarse en seguida a generar un Código anotado y concordado, parcial o total, como ocurre en Estados Unidos. Por cierto que si el Estado continuara no interesándose en este proyecto y si los números permitieran realizar este esfuerzo bajo un esquema de negocios, su ejecución por parte de LexisNexis sería más que bienvenida". También véase a Monnt Oyarzún, S., "Codificación y enseñanza del Derecho administrativo en Chile", en Revista de Derecho Administrativo Económico $\mathrm{N}^{\circ} 21$, julio-diciembre 2015, pp. 131-170.

${ }^{9}$ Es por ello que este autor señala que es difícil hablar de un Derecho Administrativo Común, por lo que sostiene que, en pos de la seguridad jurídica, convendría reconocer la falta de desarrollo de dicha disciplina y aceptar su remisión al Derecho Común en los casos de lagunas. En Bermúdez Soto, J., Derecho Administrativo General, Editorial LegalPublishing Thomson Reuters, Santiago, 2014, $3^{\text {a }}$ edición, pp. 48-49.

${ }^{10}$ García de Enterría, E. y Fernández, T. R., Curso de Derecho Administrativo, Tomo I, Editorial Civitas Thomson Reuters, Madrid, 2011, 15ª edición, p. 76. 
necesidad de administrar el Estado se adelanta a la ley ${ }^{11}$. Sostenía este autor que el Derecho Administrativo era una disciplina aún en evolución y que su teoría no se puede estimar consolidada, debido al estado de maduración de sus conceptos e instituciones, por lo que no sería factible una codificación. Sin embargo, posteriormente señaló que la complejidad actual de las regulaciones de la Administración, así como la intensidad de las innumerables áreas que interviene, hace necesario, por razones de seguridad jurídica, confianza y objetividad, uniformar el sistema jurídico aplicable a la Administración ${ }^{12}$.

Intentos de esta sistemática se aprecian, por ejemplo, en las leyes:

> $\quad \mathrm{N}^{0}$ 18.575, Orgánica Constitucional de Bases Generales de la Administración del Estado, que buscó establecer un régimen común de organización administrativa y empleo público.

$>\quad \mathrm{N}^{\mathrm{o}}$ 18.834, Estatuto Administrativo de los Funcionarios de la Administración, cuyas normas se aplican supletoriamente a los otros servidores públicos que allí se enuncian mientras no se dicten los nuevos estatutos especiales a que se refiere el art.162 de ese texto normativo.

$>\quad \mathrm{N}^{\circ}$ 19.880, que establece las Bases de los Procedimientos Administrativos que rigen los actos de los Órganos de la Administración del Estado, la que actúa como matriz y marco supletorio de todos los procedimientos especiales existentes en la Administración.

$>\quad \mathrm{N}^{\circ}$ 19.886, que establece las Bases sobre contratos administrativos de suministro de bienes y prestación de servicios, que uniforma el sistema de compras de la Administración sobre dichos bienes y servicios, a causa de la ausencia de un Código de Contratación Administrativa.

Se aprecia que los intentos legislativos se orientan hacia una sistematización aislada de ciertas instituciones o regulaciones del Derecho Administrativo, sin que exista una iniciativa en orden a generar una codificación general de esta disciplina jurídica. No siendo nuestra intención ahondar en las razones de dicha decisión, estimamos que la costumbre, la falta de interés manifestada por el ejecutivo en virtud de la importancia política de otros asuntos y la efectividad reaccionaria han sido factores relevantes para esta omisión.

Mientras ello no ocurra, se seguirá adelante con una explosión legislativa casuística, en muchas ocasiones inorgánica, dispersa y, ciertamente, desconcertante y hasta esquizofrénica para la doctrina, la que mediante significativos esfuerzos trata de encasillar las nuevas creaciones en figuras familiares y reconocidas ${ }^{13}$.

11 Silva Cimma, E., Derecho Administrativo y Comparado: Introducción y Fuentes, Editorial Jurídica de Chile, Santiago, 2009, 5 a edición, p. 119. En este punto el autor sostiene que abre campo la actividad discrecional como complemento necesario.

12 Silva Cimma, E., Derecho Administrativo y Comparado: Introducción y Fuentes, Editorial Jurídica de Chile, Santiago, 2009, $5^{\text {a }}$ edición, p. 142.

${ }^{13}$ Sobre este aspecto véase a Cordero Vega, L., Lecciones de Derecho Administrativo, Thomson Reuters - La Ley, Santiago, 2015, 2a edición, pp. 17-18. 


\section{El Derecho Administrativo como sistema jurídico}

Para Alejandro Vergara, "La idea sistemática en el Derecho, al aplicarla a una disciplina específica (como por ejemplo al Derecho Administrativo, al Derecho Civil, al Derecho Penal, y a todas las otras que conforman el cosmos de disciplinas jurídicas), proporciona unidad y coherencia, y es un invaluable auxiliar para la interpretación y aplicación del Derecho vigente" 14 .

Para Rojas Calderón "la clave del pensamiento sistémico consiste en la inducción de una teoría general a partir de los sectores especiales, conectando el caso singular con los principios e instituciones generales, en un proceso de recíproca interacción, de inducción y deducción. Desde luego, la sistematización y el sistema han acompañado siempre a la ciencia jurídica; así la búsqueda de la unidad, el orden y la tendencia a generalizar la justicia han alimentado la necesidad de construir un conjunto armónico, coherente y, por ello, sistémico" 15 .

Bajo tal predicamento, la visión sistemática permite descubrir las conexiones de sentido que existen entre las normas jurídicas y las regulaciones particulares entre sí y las vinculaciones que hay entre estas con los principios del orden jurídico ${ }^{16}$.

Ahora bien, y sin perjuicio de la pluralidad de fuentes que conforman el Derecho Administrativo, este es un sistema unitario, el que debemos considerar como un sistema cerrado en el que no debieran caber los vacíos, los que en caso de existir debieran integrarse dentro de este complejo unitario y sistemático, recurriendo, en gran medida, a los principios que lo informan. Empero, esta integralidad, como lo sostiene García de Enterría, no quiere decir que el Derecho haya de absorber de una manera preceptiva la totalidad de la vida social, sino que basta con disponer una respuesta ante cualquier situación que se presente, como sería la remisión a otro ordenamiento distinto o subordinado ${ }^{17}$.

La autosuficiencia del sistema no importa su inalterabilidad, toda vez que los cambios dentro del sistema serán posibles en la medida que se descubran nuevos principios, en virtud de variaciones legales, a razón de nuevos conocimientos de la ciencia jurídica o de modificaciones jurisprudenciales, de tal modo, el sistema será objeto de ajustes propios de la evolución del mismo.

En tal contexto, el Derecho Administrativo ha sido capaz de superar las particularidades de las regulaciones especiales y ha condensado, con gran esfuerzo, las materias específicas gracias a su capacidad ordenadora, cuya clave consiste en la inducción de una

${ }^{14}$ Vergara Blanco, A., "Sistema y autonomía de las disciplinas jurídicas. Teoría y técnica de los "núcleos dogmáticos”, en Revista Chilena de Derecho, Vol. 41 N 3, Santiago, 2014, p. 969.

${ }^{15}$ Rojas Calderón, C., "Sistema e instituciones de Derecho Administrativo en legislaciones especiales", en Bocksang Hola, G. y Vergara Blanco, A. (Coords.), Público y Privado en Derecho Administrativo, Thomson Reuters - LegalPublishing, Santiago, 2014, p. 259.

${ }^{16}$ Acerca de la formación del concepto y del sistema en la jurisprudencia véase a Larenz, K., Metodología de la Ciencia del Derecho, Ariel, Barcelona, 2010, 4a edición, pp. 437 y ss.

${ }^{17}$ García de Enterría, E. y Fernández, T. R., Curso de Derecho Administrativo, Tomo I, Editorial Civitas-

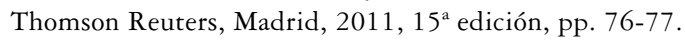


teoría general a partir de las particularidades que presentan cada uno de los sectores y en la reconducción de las piezas y soluciones singulares hacia los principios generales del Derecho (Administrativo). Esta "idea ordenadora” tiene por objeto la construcción de un sistema ${ }^{18}$.

Alejandro Vergara describe el "núcleo dogmático" del Derecho Administrativo, identificando tres temas que lo conforman: a) la existencia de la Administración, como hecho jurídico, y de su normativa; b) técnicas que crean o limitan las potestades de la Administración; y c) los derechos subjetivos públicos ${ }^{19}$.

A su vez, confirmando esta necesidad de entenderlo como un sistema, Luis Cordero Vega señala -al referirse al carácter unitario de esta rama jurídica- que es preciso que los órganos administrativos cuenten con sistemas normativos comunes que operen como elementos de garantía para los ciudadanos que se relacionan con habitualidad con ellos, además de dotar de criterios igualitarios al sistema legal que evite discriminaciones $\operatorname{arbitrarias}^{20}$.

Asimismo, no podemos dejar de mencionar en esta idea de sistema el rol que ha desempeñado y que seguirá ejerciendo la Carta Fundamental, la que a partir del reconocimiento de un amplio catálogo de derechos a los particulares ha establecido las bases de este sistema y los principios donde se ha construido la organización y el funcionamiento de la Administración Estatal, limando el ejercicio de ciertas potestades públicas en aras de mayores garantías para los ciudadanos ${ }^{21}$.

Por su parte, la jurisprudencia, tanto judicial como administrativa, también ha contribuido en el esfuerzo unificador del complejo administrativo en un todo institucional armónico y coherente ${ }^{22}$, en un comienzo mediante la incorporación de figuras foráneas recogidas de sistemas comparados (francés, español y anglosajón, posteriormente), y luego por la integración de lagunas mediante la técnica de los principios jurídicos ${ }^{23}$.

${ }^{18}$ Schmidt-Assmann, E., La teoría general del Derecho Administrativo como sistema, Marcial Pons/Instituto Nacional de Administración Pública, Madrid, 2003, p. 2.

${ }^{19}$ En palabras del autor, el concepto y técnica de un "núcleo dogmático" para cada disciplina tiene una doble función: i) desde una perspectiva epistemológica, es el origen y explicación de estatuto científico autónomo de una disciplina; y ii) desde la perspectiva de la Teoría del Derecho, como parte del instrumental abstracto-conceptual, puede prestar servicios a la dogmática, permitiendo diseccionar de la masa normativa aquellas partículas de una naturaleza singular y concreta que conforman una misma disciplina, con el objetivo de darle sentido y coherencia a su interpretación y aplicación. Vergara Blanco, A., El Derecho Administrativo como sistema autónomo. El mito del código civil como Derecho Común, AbeledoPerrot-LegalPublishing, Santiago, 2010, p. 9.

${ }^{20}$ Cordero Vega, L., "La supletoriedad en la Ley de bases de procedimiento administrativo", en Acto y procedimiento administrativo, Actas de las Segundas Jornadas de Derecho Administrativo, Ediciones Universitarias de Valparaíso, Valparaíso, 2007, pp. 54-55.

${ }^{21}$ Ferrada Bórquez, J. C., "El sistema de Derecho Administrativo chileno: una revisión crítica desde una perspectiva histórica”, en Revista de Derecho Universidad de Concepción N ${ }^{\text {os }}$ 217-218, 2005, p. 117.

${ }^{22}$ Al respecto ver a Pantoja Bauzá, R., Tratado de Derecho Administrativo. Derecho y administración del Estado, Tomo I, AbeledoPerrot - LegalPublishing, Edición Bicentenario, Santiago, 2010, pp. 47 y ss.

${ }^{23}$ Tales como los principios de confianza legítima, de impugnabilidad, la prescripción o figuras como el decaimiento. 
De esta manera, como lo expone Juan Carlos Ferrada, el Derecho Administrativo nacional "se erige como un régimen jurídico excepcional, propio y singular de la Administración Pública, que regula la organización y atribuciones de los órganos que componen esta, con cierta prescindencia de la normativa general dispuesta para los demás sujetos de derecho" 24 .

Contrario a lo previamente expuesto, alguna doctrina ${ }^{25}$ señala que el Derecho Administrativo no constituye un ordenamiento jurídico completo, y que en suma, se trataría de una disciplina carente de ordenación y de precaria densidad normativa. Postulan que frente a los vacíos normativos en el Derecho Administrativo se debe recurrir a normas de otros ordenamientos ${ }^{26}$ (verbigracia civil, penal o financiero) para llenar los vacíos propios de la cultura positivista, precisando que el Derecho Administrativo no ofrece soluciones normativas a problemas relacionados con sus propias instituciones, que es el resultado de una transformación de instituciones, que carece de una jurisdicción propia, que otras disciplinas tienen como base disposiciones de otras ramas dogmáticas (como el Código Civil), que razones de certeza, seguridad jurídica y equidad justificarían esta especie de "huida"27.

Lo cierto es que, y en este punto sigo a García de Enterría y Fernández, la utilización de la Administración de formas y técnicas privadas se pone de relieve por el hecho de que siempre encontramos en el fondo de dicha utilización un "núcleo público"28, que acompaña o precede inexcusablemente a toda actuación de Derecho Privado de la Administración. Además, no podemos olvidar que el ejercicio del "poder público" solo se justifica en la ley y no en el arbitrio de un particular ${ }^{29}$.

\footnotetext{
${ }^{24}$ Ferrada Bórquez, J. C., "Los principios estructurales del Derecho Administrativo chileno: un análisis comparativo", en Revista de Derecho Universidad de Concepción Nos 221-222, 2007, pp. 113-114.

25 Bermúdez Soto, J., Las relaciones entre el derecho administrativo y el derecho común, AbeledoPerrotThomson Reuters, Santiago, 2012, p. 64-65. También en Bermúdez Soto, J., Derecho Administrativo General, Editorial LegalPublishing, Santiago, 2014, $3^{\mathrm{a}}$ edición, 794 pp.

${ }^{26}$ Acerca de las relaciones del Derecho Administrativo con las ramas del Derecho ver Silva Cimma, E.,


2009 , pp. 50 y ss.

${ }^{27}$ En Pascual García, J., "La huida del Derecho Administrativo, del Presupuesto y de los controles financieros por los nuevos entes del sector público", en Presupuesto y Gasto Público 60, Secretaría General de Presupuestos y Gastos, Instituto de Estudios Fiscales, 2010, p. 110. En dicho texto el autor señala que es un lugar común hacer referencia a la expresión "huida del Derecho administrativo", la que se emplea para referirse a las consecuencias de la creación de distintas fórmulas organizativas en el ámbito del sector público que, pese a perseguir fines de interés general, su personalidad es privada o que, aun ostentando la condición de organismo público, se rigen en mayor o menor medida por el derecho privado.

28 Por ejemplo, los autores precisan que aun cuando las sociedades estatales se constituyan como sociedades anónimas y actúen conforme a las normas de Derecho Privado, requieren de forma previa de la emisión de un acto de carácter público. Lo mismo ocurre con la organización de los servicios públicos, los que pueden ser constituidos mediante fórmulas públicas o privadas, pero si se opta por la segunda de ellas, esta obedece a una decisión de carácter público, en García de Enterría, E. y Fernández, T.R., Curso de Derecho Administrativo, Tomo I, Editorial Civitas-Thomson Reuters, Madrid, 2011, 15ª edición, pp. 61 y ss.

${ }^{29}$ García de Enterría, E. y Fernández, T. R., Curso de Derecho Administrativo, Tomo I, Editorial CivitasThomson Reuters, Madrid, 2011, 15 a edición, pp. 61-62.
} 
Así, si bien parece que ciertas instituciones administrativas son una mera copia de instituciones privatistas, como sería la nulidad, la contratación, la responsabilidad o el régimen de los bienes públicos, una mirada más profunda en el tema deja en evidencia que cada una de estas instituciones presenta rasgos y particularidades propios, es decir, contienen en su ADN el gen administrativista, lo que demuestra que ha sido la evolución y la necesidad dentro de la sociedad lo que las ha ido construyendo, si bien a partir de disciplinas foráneas que paulatinamente han ido evolucionado en modelos dotados con un carácter propio y singular, ello a partir de los aportes efectuados por la jurisprudencia, el legislador e indudablemente, por la doctrina.

Recurriendo a representaciones gráficas, es posible esquematizar el Sistema del Derecho Administrativo de la siguiente manera:

Esquema del Sistema del Derecho Administrativo

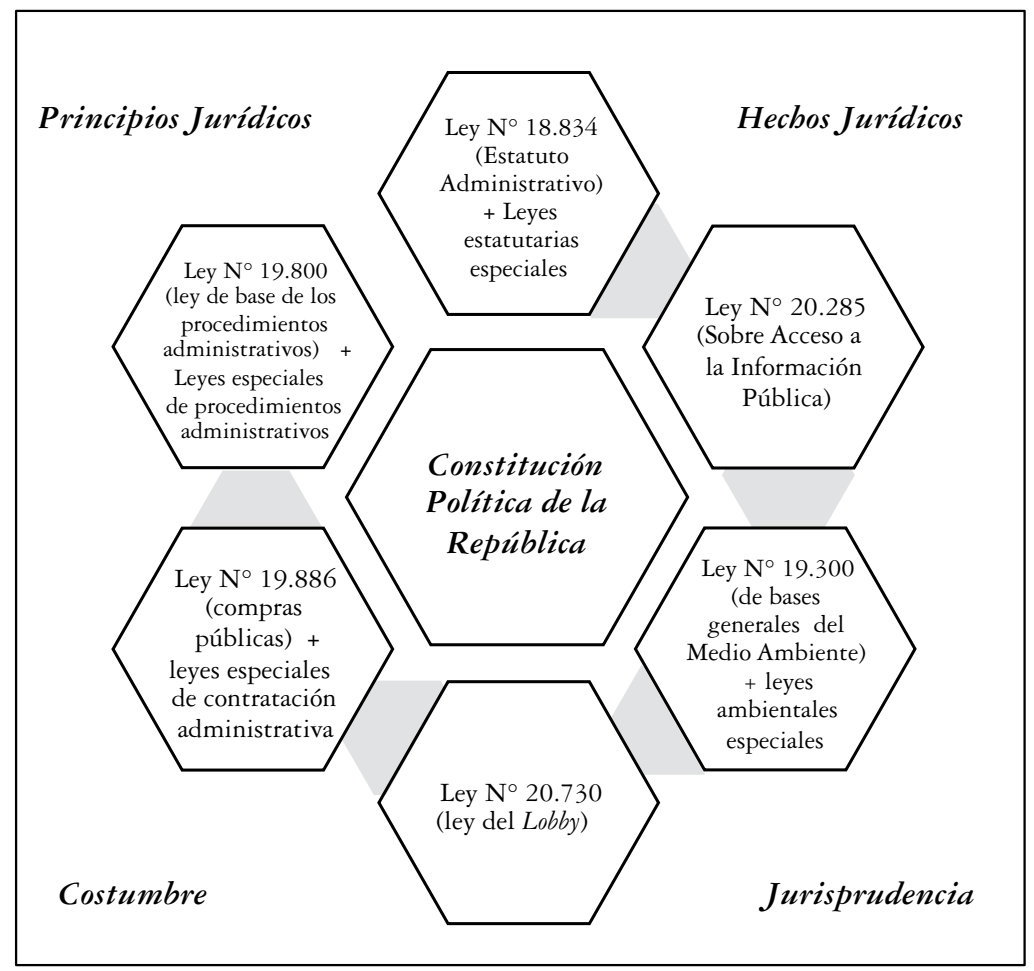

En donde el conjunto de hexágonos representan al Derecho Administrativo, que tiene como centro de su sistema a la Constitución Política de la República. Luego, lo integran diversos microsistemas de leyes especiales (donde, sin el ánimo de ser exhaustivos, se señalan solo ciertos preceptos a modo de ejemplo), algunos de estos cuentan con una ley 
de base. Rodean este conjunto armónico los principios jurídicos propios de la disciplina del Derecho Administrativo, los hechos jurídicos, que se manifiestan en el actuar cotidiano de los ciudadanos en sus relaciones de relevancia jurídica ${ }^{30}$, la costumbre, contenida en el sentimiento y conciencia jurídica popular, y la jurisprudencia de distinto orden (judicial, administrativa y constitucional), como fuentes integradoras del sistema frente a situaciones no resueltas o abordadas por las normas.

Considerar al Derecho Administrativo como un sistema, permite efectuar un análisis coherente y ordenado de las normas jurídicas vigentes, principios, costumbres y decisiones jurisprudenciales que lo estructuran, brindándole una cohesión interna y una sólida unidad que permiten su autonomía y suficiencia. De tal modo, su integralidad ayudará a atender las lagunas e inconsistencias que se presenten, teniendo en especial consideración las particularidades que estructuran cada una de sus instituciones.

\section{LAS LEYES DE BASES Y SU IMPORTANCIA en el sistema del Derecho Administrativo}

García de Enterría señalaba que el Derecho Administrativo "es un hijo directo de la consagración del sistema revolucionario del "reino de la ley", el que supone la legalización concreta de toda la acción del Estado sobre los ciudadanos, a quienes únicamente "en virtud de una ley" se puede exigir obediencia" 31 , ello encuentra correspondencia en nuestro ordenamiento jurídico en el artículo $6^{\circ}$ de nuestra Carta Fundamental, que consagra el principio de legalidad. Así, debido a la exigencia previa de un texto legal como habilitante para la actuación y ejercicio de prerrogativas públicas, la regla general corresponde a las leyes ordinarias, salvo que la propia Constitución exija una ley de distinta categoría, como sería una ley orgánica o una de quórum calificado.

En tal escenario las leyes de bases -que pueden incidir en materias como procedimientos sancionadores, concesionarios, de calificación, de admisión, entre otros- no se asoman como un tipo normativo específico, sino que solo se hizo una breve referencia a ellas en los artículos 38 y 63 N 18 y 20, todos de la Carta Fundamental, sin esbozar su concepto ni cuál sería su contenido específico y estructura concreta ${ }^{32}$.

Las leyes de bases dentro del Derecho Administrativo se han presentado como preceptos que buscan consolidar, unificar e integrar un determinado microsistema, de modo tal que su contenido sea empleado de manera supletoria frente a la aplicación de una ley

${ }^{30}$ Para Alejandro Vergara en el actuar cotidiano de los ciudadanos se puede observar el sentimiento popular de lo que es "justo" o "equitativo", así como en las costumbres: es el espíritu del pueblo; la conciencia jurídica popular; el derecho vivido. En Vergara Blanco, A., "Sistema y autonomía de las disciplinas jurídicas. Teoría y técnica de los “núcleos dogmáticos”, en Revista Chilena de Derecho, Vol. 41 No 3, Santiago, 2014, p. 962.

${ }^{31}$ García de Enterría, E., Democracia, Jueces y Control de la Administración ${ }^{6}$, Editorial Aranzadi, Navarra, 2009, pp. 55-56.

${ }^{2}$ Pantoja Bauzá, R., Tratado de Derecho Administrativo. Derecho y administración del Estado, Tomo I AbeledoPerrot-LegalPublishing, Santiago, Edición Bicentenario, 2010, pp. 152-153. 
especial o una colección de leyes. Dentro de sus funciones está servir de sustento a los jueces y legisladores, para que sea considerada por los primeros al momento de resolver algún caso vinculado con la materia específica (herramienta de interpretación judicial) y, por los segundos, a la hora de dictar nuevos preceptos, vinculándolos con aquellas ${ }^{33}$. Finalmente, su principal objeto es dar certeza y seguridad jurídica a los sujetos regulados por el microsistema respectivo.

Algunos autores y la propia historia de la Ley $\mathrm{N}^{\circ} 19.880$ las definen como aquellas que deben establecer solo los elementos básicos, fundamentales y esenciales de la regulación, dejando a la potestad reglamentaria del Presidente de la República la ejecución del respectivo precepto, acorde a las directrices y principios predeterminados. Fórmula que se justificaría plenamente por la complejidad de las labores técnicas que desarrolla la Administración y por sus constantes mutaciones ${ }^{34}$.

Un concepto que estimamos que se aproxima a este tipo de leyes es el empleado por Christian Rojas Calderón quien acuña la terminología leyes cabeceras de grupos normativos, definiéndolas como aquellas que dan coherencia y unidad a las normas de la misma naturaleza, que permiten interpretar sistémicamente las disposiciones que aparecen ligadas a estas leyes con mayor o menor cercanía, y proveen de soluciones ante lagunas legales ${ }^{35}$.

Con todo, podemos sostener que lo que distingue a una ley de bases respecto de otro tipo de normas, lejos de su denominación formal como ley de bases propiamente tal, es su contenido, toda vez que este presenta un carácter básico en su regulación, fijando las reglas y principios mínimos que se estiman sustanciales para la materia respectiva ${ }^{36}$. Se trata de pautas de orientación que establecen criterios que pueden -y deben, en ciertos casos- ser utilizados en ámbitos carentes de una regulación expresa. Buscan contribuir a la creación de microsistemas más ordenados, determinados y precisos, y de este modo, más abarcables, mediante la configuración de procesos uniformes y armónicos. Es por ello que utilizan un lenguaje jurídico claro y presentan una estructura ordenada de sus disposiciones. Por tanto, toda ley que reúna estas características podrá ser considerada

${ }^{33}$ En este sentido, conviente hacer presente que el Mensaje Presidencial de la Ley $\mathrm{N}^{\circ} 19.300$, de Bases Generales del Medio Ambiente, señaló que "La importancia capital de este proyecto de ley, es que toma definiciones que enmarcarán la discusión de una serie de proyectos de ley que vendrán en el futuro”, p. 14.

${ }^{34}$ Bulnes, L., "Leyes de base y potestad reglamentaria en la Constitución de 1980", en Revista de Derecho de la Pontificia Universidad Católica de Valparaíso, Vol. 6, 1982, pp. 140 y 141; e Historia de la Ley $\mathrm{N}^{\circ} 19.880$, que Establece base de los procedimientos administrativos que rigen de los órganos de la administración del Estado, p. 6.

${ }^{35}$ Rojas Calderón, C., "Sistema e instituciones de Derecho Administrativo en legislaciones especiales", en Bocksang Hola, G. y Vergara Blanco, A. (Coords.), Público y Privado en Derecho Administrativo, Thomson Reuters-LegalPublishing, Santiago, 2014, p. 259.

36 Respecto del carácter básico y general de la Ley N 19.880 véase el interesante análisis que ofrece Rojas Calderón, C., Las potestades administrativas en el Derecho Chileno. Un estudio dogmático-jurídico en torno a su configuración. Estructura y efectos, LegalPublishing-Thomson Reuters, Santiago, 2014, pp. 157 y ss. 
una ley de bases, sin perjuicio de la potestad reglamentaria de ejecución que el Ejecutivo pueda ejercer sobre ellas ${ }^{37}$.

A nuestro juicio, la exigencia constitucional de que toda norma de carácter general y obligatoria que estatuya las bases esenciales de un ordenamiento jurídico sea materia de ley, es un indicativo de que el constituyente busca establecer una garantía en beneficio de los derechos de los ciudadanos. En efecto, mediante la dictación de preceptos que contengan regulaciones uniformes y ordenadas para la emisión de los actos administrativos de la generalidad de los órganos públicos se busca resguardar su efectiva vigencia en la praxis. El reconocimiento y la fijación por escrito de una prerrogativa y la forma en que esta podrá ser ejercida, constituyen la expresión más primaria de una garantía ${ }^{38}$.

Así, el particular, frente a la existencia de una ley de base, contará con una valiosa herramienta jurídica que le proporcionará certeza y seguridad a sus actuaciones, que lo habilitará para ejercer en condición igualitaria sus derechos y que le permitirá efectuar un control homogéneo de los actos administrativos de acuerdo con los fines, objetivos y orientaciones de cada uno de ellos.

Como las características de este tipo de leyes podemos enunciar las siguientes:

i. Establecen las garantías esenciales o mínimas de los particulares respecto del ejercicio de una actividad administrativa determinada frente a los órganos públicos (transversalidad).

ii. Regulan la forma y modalidad, esto es, las pautas comunes, de las relaciones que deben practicarse entre el ciudadano o funcionario y la Administración.

iii. Recientes leyes de bases contienen un catálogo de los principios que informarán las actuaciones administrativas, ello en el ejercicio de una innovadora técnica legislativa de captura en donde se recogen principios existentes y se procede a su escrituración, decisión destacable que no ha estado exenta de críticas ${ }^{39}$.

37 Pese a que el artículo $63 \mathrm{~N}^{\mathrm{o}} 20$ de la Constitución emplea conceptos jurídicos indeterminados, no cabe duda de que toda norma de carácter general y obligatoria que estatuya las bases esenciales de un ordenamiento jurídico deberá ser regulada mediante una ley, sin perjuicio de la posibilidad de que el ejecutivo decida dictar los reglamentos de ejecución que estime pertinentes para el desarrollo de dichos preceptos tal como aconteció, en la especie, con la Ley N 19.886 y su reglamento. Al respecto véase a Cordero Quinzacara, E., "Los principios y reglas que estructuran el ordenamiento jurídico chileno", en Revista Ius et Praxis, año 15 - No 2, 2009, p. 23 y 44; Guiloff, M., "Operativizando la relación ley-reglamento: una propuesta de redefinición del rol de la reserva legal”, en Revista de Derecho Valdivia, Vol. XXV No 1, 2012, pp. 138 y ss.; Cazor, K. y Guiloff, M., "La reserva de ley y la necesidad de redefinir su función en el Estado Constitucional Chileno", en Anuario de Derecho Público Universidad Diego Portales, No 1, 2011, pp. 486 y ss., y Bulnes, L., "Leyes de base y potestad reglamentaria en la Constitución de 1980", en Revista de Derecho de la Pontificia Universidad Católica de Valparaíso, Vol. 6, 1982, pp. 140 y ss.

${ }^{38}$ Véase el interesante análisis que hace Eduardo Aldunate sobre la garantía de los derechos. En Aldunate Lizana, E., Derechos Fundamentales, LegalPublishing, Santiago, 2008, pp. 77 y ss.

${ }^{39}$ En tal sentido Vergara Blanco, A., "El legislador crea reglas y no principios", en El Mercurio Legal de 28 de febrero de 2013. Disponible en: http://www.elmercurio.com/Legal/Noticias/Analisis-Juridico/2013/02/28/ El-legislador-crea-reglas-y-no-principios.aspx 
iv. En ciertas circunstancias actúan como normas derogatorias ${ }^{40}$.

v. Tienen una vocación de generalidad y permanencia para el microsistema jurídico de que se trate.

vi. Son dispuestas como una norma de carácter supletorio frente a regulaciones especiales $^{41}$.

Sin duda, la existencia de leyes de bases es de suma importancia para la regulación del microsistema de que se trate dentro del Derecho Administrativo, ya que le brinda coherencia y cohesión a las múltiples instituciones que lo pueden integrar, estableciendo directrices claras para los particulares obligados por ella. De esta manera unifica y armoniza el sistema configurando el marco matriz de actuación de los particulares en relación con la Administración, operando como un instrumento protector de garantías y básico para ejercer ciertos derechos y prerrogativas.

Además, las leyes de bases contemplan una orgánica conformada por un conjunto de instituciones y principios jurídicos que son de significativa importancia por su especial lógica y lenguaje, en donde las primeras concurren a la estandarización de la interpretación jurídica, estableciendo parámetros certeros respecto de la operatividad de las reglas del microsistema, otorgando estabilidad y previsibilidad al mismo; mientras que los segundos contribuyen en la vital tarea integradora de los jueces frente a la existencia de lagunas normativas, actuando como llenadores de vacíos.

Sin embargo, en materia de leyes de base se está al debe en muchos aspectos. Se extraña, por ejemplo, la existencia de una ley de base en materia sancionadora administrativa $^{42}$, sobre todo si consideramos la gran cantidad de procedimientos sancionatorios

${ }^{40} \mathrm{Al}$ efecto, Alejandro Vergara señala que el inciso segundo del artículo 139 del Código de Aguas (en lo que respecta a las resoluciones relativas al procedimiento de constitución de las concesiones de aguas), deben notificarse al interesado, en lo que interesa, al domicilio que este haya designado dentro de los límites urbanos del lugar en que funciona la oficina donde se haya efectuado la presentación; agregando su inciso tercero que "Si no se hace esta designación la resolución se entenderá notificada desde la fecha de su dictación". En otras palabras, como sanción por la omisión de designar un domicilio "se entiende" (ficción legal o presunción) que el interesado se ha notificado de la resolución respectiva. En palabras del autor, se trataría de una no notificación, agregando que conforme a los principios consagrados en la Ley $\mathrm{N}^{\circ} 19.880$ (publicidad y conocimiento de los actos administrativos individuales), es posible considerar derogado tácitamente la citada disposición, ya que los artículos 10, 15, 16, 17 y 45 a 47, de la anotada Ley $\mathrm{N}^{\circ} 19.880$ son normas que constituyen "bases" regulatorias aplicables a todo procedimiento administrativo. En Vergara Blanco, A., "Modificación del marco regulatorio de las aguas por medio de Actos de Orden Interno emanados de la Dirección General de Aguas", en Actas de Derecho de Aguas No 2, 2012, pp. 264 y ss.

${ }^{41}$ Acerca de esta última característica, Eduardo Soto Kloss, refiriéndose a la Ley $N^{\circ} 19.880$, señala que es curioso que una "ley que fije las bases" que se supone que establece los "fundamentos" del ordenamiento sectorial, sea una ley supletoria de un abigarrado, multifacético y heterogéneo conjunto de normas procedimentales administrativas que suman cerca de dos millares, característica que a su juicio implicaría una aplicación meramente residual de la ley. En Soto Kloss, E., Derecho Administrativo Temas Fundamentales, AbeledoPerrot-Thomson Reuters, Santiago, 2012, 3ª edición, pp. 328-329.

${ }^{42}$ Es admisible tener presente que mediante el Boletín $\mathrm{N}^{0} 3475-06$ se presentó por parte del Presidente de la República, ante el Senado, un proyecto de ley que establecía las bases de los procedimientos administrativos sancionatorios, en dicho texto se efectuó un reconocimiento expreso de la potestad administrativa 
existentes (sanitario, ambiental, eléctrico, educacional, entre otros), desprovistos de una orgánica uniforme y precisa de reglas y principios claros para el ejercicio de la potestad represiva del Estado, lo que deja al particular en un terreno muchas veces sorpresivo e inclusive, en ciertas ocasiones, a un paso de solicitar la declaración de inconstitucionalidad de la norma.

En efecto, es una constante ver cómo en sede judicial y constitucional se ventilan sendos problemas generados por la falta de una orgánica sancionatoria de la Administración, discutiéndose desde las garantías aplicables a los sancionados, distintas particularidades del procedimiento, la aplicación de ciertos principios penales de orden constitucional, plazos de prescripción, transmisibilidad de las sanciones, responsabilidades solidarias y objetivas, la eficacia de sanciones administrativas que implican la privación de libertad, la aplicación de figuras como los concursos penales (real, aparente, ideal), la necesidad de efectuar una consignación previa para reclamar del acto sancionatorio ante los Tribunales de Justicia (solve et repete), en fin, un sinnúmero de entresijos difícilmente superables, sobre todo si se tiene en consideración las enormes exigencias demandadas por el principio de legalidad respecto de la materia.

Finalmente, es importante agregar que la aplicación de estas leyes de base es meramente residual, esto es, opera frente a la ausencia de una regulación clara o precisa en el microsistema respetivo ${ }^{43}$, esto le resta efectividad e importancia práctica al momento de proteger eficazmente los derechos y garantías de los particulares sujetos a su regulación.

\section{Conclusiones}

El Derecho Administrativo, como disciplina jurídica, constituye un todo armónico, un sistema unitario conformado por varios microsistemas que lo integran y que se sustentan en ciertas reglas, instituciones y principios que le son inherentes. Sistema que se estructura en una respetuosa base protectora de los derechos y garantías consagrado en la Constitución para los particulares que a diario interactúan con ella. Lo anterior pese a que la dispersión normativa ha sido a lo largo de su historia una de sus principales características, debido a su carácter reaccionario frente a los constantes cambios producidos en la sociedad regulada a la que está adscrito.

Como se aprecia, no existe un "código" al respecto que establezca de un modo uniforme y coherente el núcleo del Derecho Administrativo, cuestión que si bien se estimó impensado por su carácter evolutivo y necesidad de imperiosa eficacia en su actuar; hoy consideramos que sería una herramienta de significativa relevancia para los particulares

\footnotetext{
sancionadora, haciendo presente el apremio por instaurar una regulación legal tendiente a controlar el poder de la Administración, para así evitar que este sea inconsulto, arbitrario e ilimitado. El proyecto descansó en normas fundamentales como la dignidad y el respecto por la persona. Fue archivado en agosto de 2006 cuando se encontraba en primer trámite constitucional.

${ }^{43}$ Así, la Ley $\mathrm{N}^{\circ} 19.880$ suplió todas aquellas leyes anteriores a su vigencia en cuyos textos no indicaban en forma precisa la forma de cómputo de sus plazos.
} 
sujetos a su regulación como una garantía de certeza, seguridad jurídica y objetividad. Además, de proporcionar al sistema directrices claras y estándares uniformes en los diversos microsistemas.

Con todo, las leyes de bases han venido a cumplir un rol integrador en determinados microsistemas, brindándoles a los particulares reglas claras para el ejercicio de prerrogativas determinadas. Sin embargo, su estructura dista mucho de satisfacer la necesidad de un código, encontrándose a años luz de siquiera ser consideradas como tales. Su carácter supletorio, su ausencia de vocación general y su precaria utilización (solo en ciertos ámbitos) hacen que no tengan la fuerza sistémica necesaria para proteger los derechos y garantías de los particulares frente a la Administración con suficiente eficacia.

\section{BIBLIOGRAFÍA}

Aldunate Lizana, E., Derechos Fundamentales, LegalPublishing, Santiago, 2008, pp. 439.

Bermúdez Soto, J., Derecho Administrativo General, LegalPublishing-Thomson Reuters, Santiago, $3^{\text {a }}$ edición, 2014, 794 pp.

BERMúdez Soto, J., Las relaciones entre el derecho administrativo y el derecho común, AbeledoPerrotThomson Reuters, Santiago, 2012, 127 pp.

Bulnes, L., "Leyes de base y potestad reglamentaria en la Constitución de 1980", en Revista de Derecho de la Pontificia Universidad Católica de Valparaíso, Vol. 6, 1982, pp. 133- 153.

Cazor, K. y Guiloff, M., "La reserva de ley y la necesidad de redefinir su función en el Estado Constitucional Chileno", en Anuario de Derecho Público Universidad Diego Portales, $\mathrm{N}^{\circ} 1$, 2011, pp. 478-501.

Cordero Quinzacara, E., "Los principios y reglas que estructuran el ordenamiento jurídico chileno", en Revista Ius et Praxis, año 15 - No 2, 2009, p. 11-49.

Cordero Vega, L., La supletoriedad en la Ley de bases de procedimiento administrativo, en Acto y procedimiento administrativo, Actas de las Segundas Jornadas de Derecho Administrativo, Ediciones Universitarias de Valparaíso, Valparaíso, 2007, pp. 49-70.

Cordero Vega, L., Lecciones de Derecho Administrativo, Thomson Reuters - La Ley, Santiago, 2015, $2^{\mathrm{a}}$ edición, $786 \mathrm{pp}$.

Ferrada Bórquez, J. C., "El sistema de Derecho Administrativo Chileno: una revisión crítica desde una perspectiva histórica”, en Revista de Derecho, Universidad de Concepción $\mathrm{N}^{\circ}$ s. 217 218, 2005, pp. 99-118.

Ferrada Bórquez, J. C., "Los principios estructurales del Derecho Administrativo chileno: un análisis comparativo", en Revista de Derecho Universidad de Concepción $\mathrm{N}^{\circ}$ s. 221-222, 2007, pp. 99-136.

García de Enterría, E., Democracia, Jueces y Control de la Administración, Editorial Aranzadi, Navarra, 6a edición, 2009, 346 pp.

García de Enterría, E. y Fernández, T. R., Curso de Derecho Administrativo, Tomo I, Editorial Civitas Thomson Reuters, Madrid, 2011, $15^{\text {a }}$ edición, 872 pp.

Garrido Falla, F., Tratado de Derecho Administrativo, Parte General, Volumen I, Instituto de Estudios Públicos, Madrid, 1970, $5^{a}$ edición, 579 pp.

Guiloff Titiun, M., "Operativizando la relación ley-reglamento: una propuesta de redefinición del rol de la reserva legal”, en Revista de Derecho Valdivia, Vol. XXV No 1, 2012, pp. 127-147.

Irti, N., La edad de la descodificación, José María Bosch Editor, Barcelona, 1992, 214 pp.

Larenz, K., Metodología de la Ciencia del Derecho, Ariel, Barcelona, 2010, $4^{\mathrm{a}}$ edición, 536 pp. 
Montt S., "El nuevo Código Administrativo General: poniendo orden a un caos normativo al que nadie se había atrevido a enfrentar", en: Revista de Derecho Administrativo Económico, 2005, No 14, p. 197-202.

Monnt Oyarzún, S., "Codificación y enseñanza del Derecho administrativo en Chile”, en Revista de Derecho Administrativo Económico No 21, julio-diciembre 2015, pp. 131-170.

Pantoja Bauzá, R., Tratado de Derecho Administrativo. Derecho y administración del Estado, AbeledoPerrot - LegalPublishing, Santiago, Tomo I, Edición Bicentenario, 2010, 371 pp.

Pascual García, J., "La huida del Derecho Administrativo, del Presupuesto y de los controles financieros por los nuevos entes del sector público”, en Presupuesto y Gasto Público 60, Secretaría General de Presupuestos y Gastos, Instituto de Estudios Fiscales, 2010, pp. 109-128.

Rojas Calderón, C., Las potestades administrativas en el Derecho Chileno. Un estudio dogmático-jurídico en torno a su configuración. Estructura y efectos, LegalPublishing - Thomson Reuters, Santiago, 2014 , pp. 180.

Rojas Calderón, C., "Sistema e instituciones de Derecho Administrativo en legislaciones especiales”, en Bocksang Hola, G., y Vergara Blanco, A., [Coords.], Público y Privado en Derecho Administrativo, Thomson Reuters - LegalPublishing, Santiago, 2014, pp. 257-282.

Schmidt-Assmann, E., La teoría general del Derecho Administrativo como sistema, Marcial Pons/ Instituto Nacional de Administración Pública, Madrid, 2003, 475 pp.

Silva Cimma, E., Derecho Administrativo y Comparado: Introducción y Fuentes, Editorial Jurídica de Chile, Santiago, 2009, $5^{\text {a }}$ edición, 324 pp.

Soto Kloss, E., Derecho Administrativo Temas Fundamentales, AbeledoPerrot-Thomson Reuters, Santiago, 2012, $3^{\text {a }}$ edición, 966 pp.

Vergara Blanco, A., "El Derecho Administrativo como sistema autónomo. El mito del código civil como Derecho Común”, Abeledo Perrot-Legal Publishing, Santiago, 2010, 150 pp.

Vergara Blanco, A., "Modificación del marco regulatorio de las aguas por medio de Actos de Orden Interno emanados de la Dirección General de Aguas”, en Actas de Derecho de Aguas $\mathrm{N}^{\circ}$ 2, 2012, pp. 253-268.

Vergara Blanco, A., "Sistema y autonomía de las disciplinas jurídicas. Teoría y técnica de los 'núcleos dogmáticos”, en Revista Chilena de Derecho, Vol. 41 N 3, Santiago, 2014, pp. 957-991.

Vergara Blanco, A., "Uso doctrinario de la expresión 'código'. Caso Editorial Jurídica de Chile con Editorial Lexis Nexis”, en Revista de Derecho (Valdivia). Vol. XXVIII N 1 , junio 2015, pp. 265-276.

\section{Normativa Citada}

Constitución Política de la República de Chile.

LEY N N $^{\circ}$ 8.575, Orgánica Constitucional de Bases Generales de la Administración del Estado.

LEY $\mathrm{N}^{\circ} 18.834$, Estatuto Administrativo.

LEY N $\mathrm{N}^{\circ}$ 19.300, sobre Bases Generales del Medio Ambiente.

LEY N $N^{\circ}$ 19.880, que Estableció Bases de los Procedimientos Administrativos que Rigen los Actos de los Órganos de la Administración del Estado.

LEY N $\mathrm{N}^{\circ}$ 19.886, que establece las Bases sobre contratos administrativos de suministro de bienes y prestación de servicios.

LEY N $\mathrm{N}^{\circ}$ 20.285, Sobre Acceso a la Información Pública.

LEY N 20.730, que Regula el Lobby y las gestiones que representen intereses particulares ante las autoridades y funcionarios. 